\title{
Better obstetric outcomes
}

\author{
Fiona Godlee editor, BMJ
}

Fatima Aliyu was 25 years old when she went into labour with her first child. Six days later, the baby was dead-stillborn by caesarean section - and Fatima had lost control of her bladder and bowels. "I cried in the dark because I was left behind, my dignity was gone," she writes (doi:10.1136/bmj.d2881). Ten years on, still struggling with the effects of her prolonged obstructed labour, with two obstetric fistulas, sphincter damage, and foot drop, Fatima is nonetheless one of the lucky ones. Despite the social stigma and huge practical challenges of her incontinence and her inability to have other children, her family has stood by her. She has also had specialist surgery. Of the estimated two million women who live with the effects of obstetric fistula, most are ostracised and fall into extreme poverty. And according to Gloria Esegbona's accompanying commentary, at best only 10-20\% will get the surgical care they need.

Obstetric fistula is a disease of poverty and is almost entirely preventable. What Fatima lacked, in common with most of the estimated 350000 women who die each year in pregnancy and childbirth (http://bit.ly/mBKsis), was timely access to skilled obstetric care. Esegbona acknowledges the crucial importance of tackling the wider social and cultural issues-poverty, lack of education for girls, early marriage, and pregnancy. But she is clear that even if these were addressed, without improvements in obstetric care women will still suffer the effects of ignorance and neglect during labour that lead to serious pelvic damage.

Achieving the necessary improvements in obstetric care in developing countries is far from simple. In this week's Head to
Head, Joseph Ana (doi:10.1136/bmj.d3310) and Kelsey Harrison (doi:10.1136/bmj.d3308) argue out the pros and cons of one approach - the training of traditional birth attendants. WHO suggests that, until sufficient numbers of skilled midwives are ready to live in villages where their services are most needed, the best policy is to identify, train, and support traditional birth attendants. Ana agrees, citing a randomised controlled trial published a few weeks ago in the $B M J$, which found that training traditional birth attendants in Zambia significantly reduced neonatal mortality (BMJ 2011;342:d346). But Harrison argues that traditional birth attendants have little or no place in the better future that women in developing countries are now demanding. He says it's hard to justify investing in traditional birth attendants. "Their use is a distraction in that it seeks to manage extreme poverty instead of working to eliminate it." Of course skilled obstetric care, however achieved, is only one essential factor in reducing maternal mortality and morbidity. Also crucial is the provisions of safe and effective contraception. WHO says that this is still not available to around 215 million women who would prefer to delay or avoid pregnancy, and it estimates that satisfying this unmet need could cut the number of maternal deaths by almost a third. As the clock ticks towards 2015 , how much more progress can the world make towards the fifth millennium development goal: reduction in maternal mortality by three quarters and universal access to reproductive health?

Cite this as: $B M J 2011 ; 342: \mathrm{d} 3778$ 